\title{
VESTÍGIOS DO AMOR CORTÊS E A FIGURA DA MULHER NA POESIA DE ALICE RUIZ: AS RESIDUALIDADES MEDIEVAIS NA SALA DE AULA
}

VESTIGES OF COURTEOUS LOVE AND THE FIGURE OF WOMEN IN ALICE RUIZ'S POETRY: MEDIEVAL RESIDUALS IN THE CLASSROOM

Marivaldo Omena Batista ${ }^{1}$ Renata Junqueira de Souza ${ }^{2}$

1 Doutorando na Universidade Federal da Paraíba.

2 Livre-docente da Universidade Estadual Júlio de Mesquita Filho.

Via Atlântica, Sâo Paulo, n. 39, p. 162-194, set. 2021. 
Resumo: A poética de Alice Ruiz contempla um posicionamento crítico em torno do amor e do gênero. Com efeito, o artigo procura analisar os vestígios do medievo na temática do amor cortês e da mulher na poesia da compositora curitibana. A percepção destes conteúdos pode potencializar debates no espaço escolar acerca das questões culturais, históricas e sociais de uma literatura que testemunha a condição da mulher. Os estudos da Teoria da Residualidade, de Pontes (2019), e das relações entre literatura e história, de Mignolo (2001) favorecem a leitura da escrita da haicaísta. A metodologia corresponde à pesquisa bibliográfica e qualitativa, já que procura fomentar a mediação da poesia na escola.

Palavras-chave: Poesia de Alice Ruiz, mulher, amor, ensino. 
Abstract: Alice Ruiz's poetics contemplates a critical positioning around love and gender. Indeed, the article seeks to analyze the vestiges of the medieval on the theme of courteous love and women in the poetry of the Curitiba composer. The perception of these contents can enhance debates in the school space about cultural, historical and social issues in a literature that testifies to the condition of women. The studies of the Theory of Residuality, by Pontes (2019), and the relations between literature and history, by Mignolo (2001) favor the reading of the writing of the haikuist. The methodology corresponds to bibliographic and qualitative research, since it seeks to promote the mediation of poetry at school.

Keywords: Alice Ruiz's poetry, woman, love, teaching. 


\section{0 amor cortês e a mulher nas malhas culturais: a poesia de Alice Ruiz}

Os resíduos medievais em torno do amor cortês e a construção da figura da mulher são duas temáticas discutidas no campo da história e da literatura. A historiografia pós-moderna, a título de exemplo, apropria-se das ciências sociais, da cultura, da antropologia e do pós-estruturalismo para analisar as relações entre o passado e o presente. Conforme $\mathrm{Au}$ rell (2016), em O Novo Medievalismo e a interpretação dos textos históricos, o medievalista não recupera o passado através dos fatos históricos, mas analisa os resíduos do passado em contextos culturais, sociais e literários do presente.

A partir desse viés, o estudioso observa que as mudanças sociais, ou a preservação de uma herança conservadora acerca do matrimônio, do gênero e das relações entre homens e mulheres, podem ser investigadas através da construção do imaginário medieval, que é percebido nos bastidores dos acontecimentos históricos e na Literatura. Com efeito, o amor cortês e a figura da mulher no século XII são concepções preestabelecidas por uma organização política e econômica que se empenha na manutenção dos privilégios da nobreza e da Igreja a partir do jogo amoroso. Estes fenômenos de filiação ideológica e patriarcal podem reverberar nas práticas sociais e afetivas posteriores à Idade Média, como também na escrita literária. 
Diante da perspectiva da literatura contemporânea, Zolin (2009), em Crítica Feminista, observa o desenvolvimento de uma crítica literária que discute o posicionamento da mulher no contexto social, assim como aborda os discursos em torno do corpo, da sexualidade, do matrimônio e da maternidade através do feminismo. Dentro desse contexto analítico, o projeto estético de Alice Ruiz apresenta uma concepção temática que critica a preservação conservadora na relação entre homens e mulheres, na qual a figura feminina se impõe na conduta amorosa e é protagonista da sua própria história.

Por esse caminhar, a mulher na poética de Alice Ruiz é construída através de um pensamento pós-moderno, o que permite uma discussão em torno do amor e do gênero sob uma concepção feminista, ${ }^{3}$ propiciando uma percepção significativa dos signos sociais e políticos. Estes conteúdos são potencializados por uma linguagem que comunica uma troca de vivências e experiências do mundo cotidiano, direcionando, por sua vez, a poética da compositora curitibana a um ponto de vista pós-autônomo, isto é, um discurso que, conforme Ornelas (2013, p.134), "submerge nas malhas da cultura".

A partir desse viés, entendemos malhas como um tecido resultante de um processo cuidadoso, em que o

3 De acordo com Hall (2011), o feminismo foi um dos movimentos pós-modernos que contribuiu para a descentralização do sujeito, haja vista que favoreceu a uma discussão significativa sobre a sexualidade e o corpo na perspectiva da mulher. 
artesão cria peças pertinentes a um determinado período, com seus modismos, estilos e contextos. Desse modo, compreender o tecido poético pode favorecer a construção dos bastidores sociais e ideológicos da época, o que permite uma compreensão dos conflitos de um dado momento histórico, aquele em que o texto foi publicado. Ainda em consonância com Ornelas (2013), o leitor pós-autônomo lê o mundo através da poesia para apreciar e compreender a multiplicação de territórios discursivos. Sendo assim, este sujeito contemporâneo recepciona as temáticas do amor e da mulher na poética de Alice Ruiz a partir de um recorte historiográfico, como também através dos seus desdobramentos estéticos: poema lírico, poema experimental, haicai, quadrinhos e a música.

Com efeito, a propositura do nosso artigo é analisar o amor cortês como resíduo medieval e a figura da mulher na poética de Alice Ruiz. Diante dessa perspectiva, a construção dos bastidores sociais e políticos no processo estético da poeta pode ser evidenciada. No que concerne ao ensino de literatura, a projeção desses contextos discursivos propicia a formação de uma sensibilidade, que é potencializada a partir da relação texto-leitor.

Dessa forma, o fazer poético de Alice Ruiz contribui para uma experiência estética, permitindo ao jovem leitor compreender as práticas sociais e culturais do seu próprio tempo, já que as temáticas elencadas estão inseridas no nível do poético e do cotidiano. 


\section{A poética de Alice Ruiz}

Nascida em 22 de janeiro de 1946, Alice Ruiz estreou o seu percurso literário com a obra Navalhanaliga (1980). Conforme Murgel (2010), o livro é composto de poemas produzidos em meados dos anos de 1970, que contemplam as questões feministas de forma consistente. Posteriormente, vieram Paixão xama paixão (1983), Pelo pelos (1984), HAI-TROPIKAI (1985), Rimagens (1985), Vice versos (1988), Desorientais (1996), HAIKAIS (1998), Poesia pra tocar no rádio (1999), YUUKA (2004), Salada de frutas (2008), Conversa de passarinhos (2008), Dois em um (2008), Três linhas (2009), Boa companhia (2009), Nuvem feliz (2010), Jardim de haijin (2010), Proesias (2010), DOIS HAIKAIS (2011), Estação dos bichos (2011), Luminares (2012) e Outro silêncio (2015).

0 fazer poético de Alice Ruiz se desdobra em outras linguagens, como por exemplo, a música e o HQ. No que concerne às composições musicais, a poeta lançou, em 2005, seu primeiro CD, o Paralelas, ${ }^{4}$ em parceria com Alzira Espíndola, com as participações de Zélia Duncan e Arnaldo Antunes. Algumas canções abordam a subjetividade, o corpo e a sexualidade feminina. Dessa maneira, músicas como "Era uma vez", "Paralelas", “Ladainha” e “Overdose” expressam um

4 Conteúdo disponível em: http://www.aliceruiz.mpbnet. com.br/discografia/index.html 
conjunto de experiências subjetivas sob a luz da mulher.

Já o HQ Afrodite: quadrinhos eróticos, foi lançado em 1978 pela editora Grafipar e censurado no mesmo ano pelo governo autoritarista do General Ernesto Geisel. Em 2015, pela editora Veneta, houve o seu segundo lançamento. 0 livro foi roteirizado e poetizado por Alice Ruiz e Paulo Leminski. Os quadrinhos foram desenhados por Júlio Shimamoto e diagramados por Claudio Seto. A obra aborda a figura feminina, a sexualidade, o corpo e a nudez masculina e feminina a partir de um viés poético e mitológico.

Sendo assim, esse estudo está centrado em uma análise em torno do amor cortês e da figura da mulher na obra poética de Alice Ruiz, bem como da sua recepção na sala de aula.

\section{Amor Cortês e a Mulher em Alice Ruiz}

O amor é um dos eixos temáticos da poesia de Alice Ruiz, no qual é possível perceber uma crítica em torno da preservação conservadora nas relações entre homens e mulheres. Desse modo, o conservadorismo abordado nos poemas pode ser um resíduo da conduta amorosa do período medievo. 0 artigo Amor Cortês - Suas origens e significados, de Barros (2011), elenca algumas considerações significativas acerca do "Tratado do Amor Cortês", escrito no século XII por André Capelão e do amor cortês como uma forma 
de sensibilidade e de poder político centrado na nobreza e na Igreja na Idade Média.

De acordo com Barros (2011), a escrita trovadoresca foi um dos principais veículos deste novo sistema de práticas sociais e das representações de poder da nobreza e da Igreja. André Capelão, a título de exemplo, exerceu as suas atividades na corte do Conde de Champagne por volta de 1170 e procurou refletir sobre o amor à maneira dos tratadistas medievais, o que contribuiu para a elaboração de novos padrões de sensibilidade através da escrita do famoso "Tratado do Amor Cortês".

A partir desse ínterim, o cavaleiro medieval, classe esta que estava desvalorizada devido à ausência de função na corte no período medievo, foi ressignificado, já que, através do "Tratado do Amor Cortês", lhe foi atribuído, de acordo com Barros (2011), uma característica de vassalo humilde, apesar da sua altíssima posição social. Dessa forma, este homem servo dos afetos devota à dama cortejada. Ainda em consonância com o estudioso, o trovador Guilherme de Poitiers foi um dos primeiros cancioneiros que compôs, em meados do século XII, uma cantiga que projeta a conduta social e amorosa destes cavaleiros, bem como enfatiza os preceitos fundados pelo amor cortês, como, por exemplo, o aperfeiçoamento moral destes homens e a entrega de si mesmo à mulher amada: 
Pelo contrário, entrego-me a ela a ponto de deixar que me inscreva no rol dos seus criados. E não me tenhais por ébrio se amo a minha boa senhora, pois sem ela não posso viver, tal o domínio que sobre mim exerce a esperança do seu amor.

Que proveito tereis, graciosa dama, em que vosso amor de mim se distancie? Parece mover-vos a vontade de ser monja. E sabei que vos amo tanto, que chego a temer que a dor me fira, se não me reparardes as injustiças de que vos acuso. (BARROS, 2011 [1965], p. 200)

A escrita acima aborda, de acordo com Barros (2011), o diálogo entre o amor e a entrega, como também o amor e o cinismo. 0 estilo levemente irônico acerca da mulher cortejada constrói uma dama intocável, longínqua e idealizada (Parece mover-vos a vontade de ser monja), o que pode, através da conduta amorosa, esboçar um perfil de mulher que não existe.

0 "Tratado do Amor Cortês", além de construir um modelo de cavaleiro medieval, direciona a mulher a um lugar imaculado. Com efeito, a dama é adorada, ingênua e santa, associando-a a imagem e semelhança da Virgem Maria, o que pode estar próximo de um conceito de amor restritamente sagrado. A condição de santa é um critério imprescritível para a realização do jogo amoroso no medievo. A escrita de Guilherme de Poitiers, por exemplo, apresenta um perfil de mulher, que, de acordo com o discurso do cavaleiro, parece ser monja, o que a torna pura, intocável e distante do amor mundano. Por ser casta e honrada, a mulher não participa diretamente do cortejo, ela geralmente 
é seduzida pelo vassalo, assim como oferece-lhe todo o afeto, aceitando, sem questionar, tudo aquilo que a impõe neste tratado. Sendo assim, atribui-se, de acordo com Barros (2011), um papel secundário neste jogo realizado por homens e mulheres.

O HQ Afrodite: quadrinhos eróticos, de Alice Ruiz e de Paulo Leminski (2015), aborda uma reflexão crítica acerca de uma herança conservadora nas relações entre homem e mulher, uma vez que projeta nos quadrinhos a conduta amorosa a partir de um fluxo de pensamento importado do período medieval. Em "Lindes disciplinares da Teoria da Residualidade", de Pontes (2019), discute algumas considerações sobre o conceito de mentalidades. De acordo com o estudioso, os resíduos mentais são constituídos por meio de uma situação histórica, bem como das experiências culturais, estéticas e sociais importadas de um sujeito. Dessa forma, estes resquícios são consequências de uma colonização europeia, visto que a literatura luso-americana e hispano-americana apresentam resíduos mentais da cultura, da escrita, dos mitos e da utopia do colonizador.

A narrativa do quadrinho "Ele precisa de mim até quando?", de Alice Ruiz (2015), apresenta uma discussão em torno da conduta amorosa entre homens e mulheres. 0 referido quadrinho, que foi publicado e censurado no final dos anos de 1970, expressa um contexto social brasileiro que se aproxima do pensamento medievo, em que foi atribuída à mulher uma 
imagem materna, bondosa e acolhedora, a fim de atender as necessidades dos homens que a cortejam:

Figura 1 - Afrodite: quadrinhos eróticos

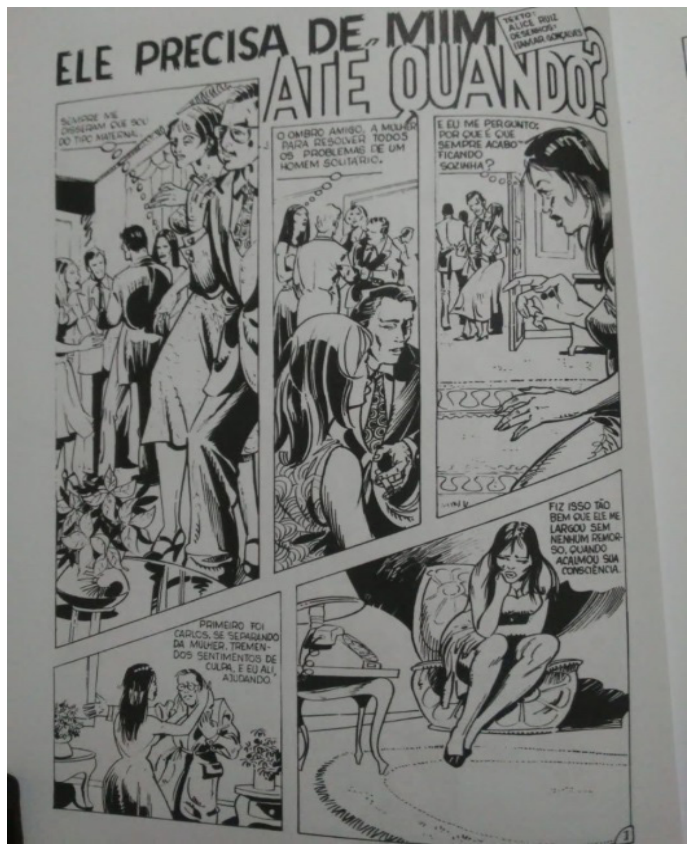

Fonte: os autores, 2020. 
Figura 2 - Afrodite: quadrinhos eróticos

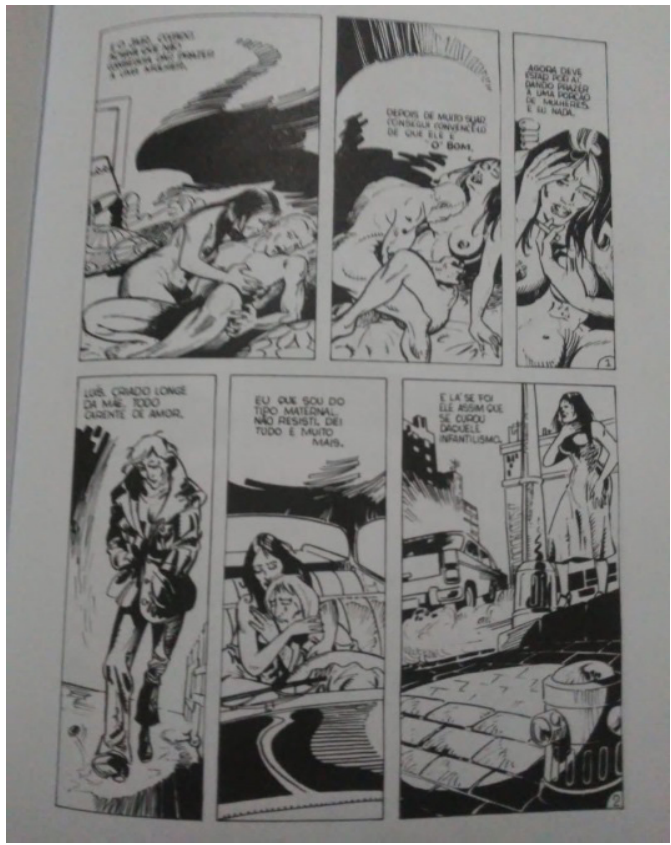

Fonte: os autores, 2020.

A protagonista/narradora do quadrinho comenta "Sempre me disseram que sou do tipo maternal". Com efeito, a narrativa inicia com um advérbio de tempo (Sempre) que pode sugerir algo contínuo no que concerne às convenções amorosas da personagem, dentro do qual o espírito acolhedor e materno molda a personalidade da protagonista. Embora não 
seja revelado quem determina a sua personalidade maternal, as digressões da narradora ao longo dos quadrinhos direcionam o leitor a perceber que as experiências afetivas desta mulher apresentam algo em comum: homens problemáticos que a recepcionaram em busca de cuidados, de atenção e de sexo.

Esta perspectiva pode construir os bastidores social e político do final dos anos de 1970. O general Ernesto Geisel foi o quarto presidente no período da ditadura militar, caracterizada por uma prática social conservadora e patriarcal, o que permitia este reflexo nas relações amorosas entre homens e mulheres. De acordo com Ridenti (1990), as mulheres ocupavam uma posição submissa na política e na sociedade brasileira. No HQ, podemos perceber esse comportamento servil e uma postura de coadjuvante. No entanto, ao questionar-se "até quando?", ela assume o protagonismo dos seus afetos e das suas ações: 
Figura 3 - Afrodite: quadrinhos eróticos

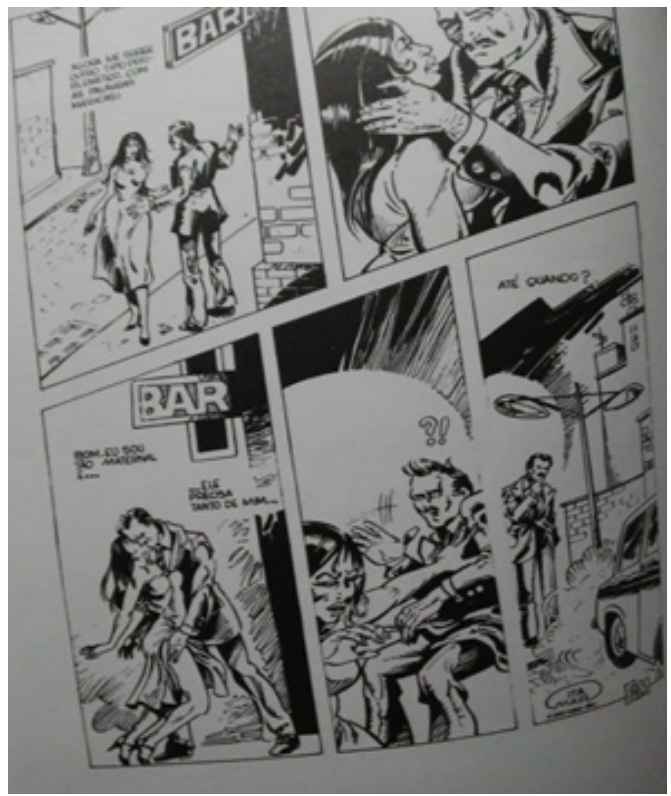

Fonte: os autores, 2020.

No que refere à narrativa do quadrinho acima, o advérbio de tempo (agora) pode possibilitar uma tensão no leitor, direcionando-o a uma ruptura da personalidade materna da protagonista. Mesmo tomada nos braços desse homem, que a beija, a personagem o empurra, foge em um veículo e questiona "até quando?". A partir desse viés, a Teoria da Residualidade, de Pontes (2019), propicia uma percepção de resíduos 
do amor cortês, favorecendo a construção do contexto social e histórico brasileiro dos anos de 1970, uma vez que a conduta amorosa no quadrinho de Alice Ruiz "Ele precisa de mim até quando" potencializou para o leitor a maneira como os grupos ideológicos e conservadores sentiam, pensavam e agiam na prática social e afetiva, como também a resistência da mulher.

Na mesma perspectiva, o poema visual "O que é a que é?", publicado no livro Navalhanaliga (1980), apresenta um lirismo que reflete a construção conservadora e machista da mulher através de um modelo de adivinha: 
Figura 4 - Poema visual "0 que é a que é?".

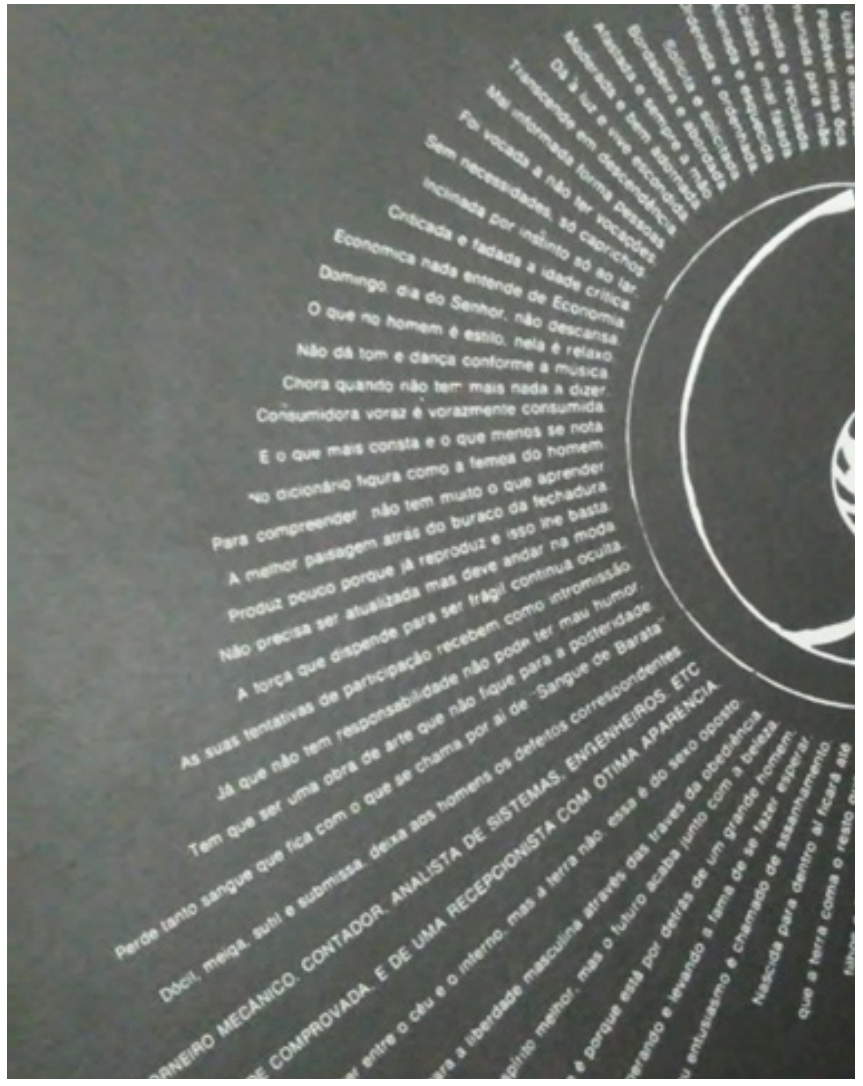

Fonte: os autores, 2020.

O título “O que é a que é?" sugere uma leitura próxima da adivinha, na qual o leitor é desafiado, através de um tom irônico, a desvendar as pistas que os 
versos propõem. A própria expressão, que nomeia o poema, apresenta um rastro estético que possibilita a descoberta da adivinhação, uma vez que há uma troca do artigo definido masculino pelo feminino /a/. No que concerne à disposição da estrutura do poema, percebemos que a sua forma pode imitar uma concha, um seio ou um óvulo, o que pode propor ao leitor uma infinidade de pistas para uma mesma resposta: a mulher. Alguns desses versos, como, por exemplo, "Usada e abusada/Palpável mas ôca/Amainada para mãe/Acusada e recuada/Calada e mal falada", constroem, de maneira estereotipada, a figura da mulher. Os outros versos evidenciam uma mulher arrumada, na moda, com características físicas que atraem os homens, evidenciando um machismo peculiar do brasileiro.

Dentro desse contexto, o "Tratado do Amor Cortês", de André Capelão, que, de acordo com Domingues (2019), em $O$ silenciamento da mulher no discurso do amor Cortês, é uma conduta social inspirado no sistema socioeconômico feudal, que é a vassalagem. Este jogo amoroso idealiza a mulher como uma figura semelhante a Virgem Maria, como também a associa à imagem de Eva, isto é, um ser persuasivo, perigoso e pecador. A função do homem é de controlar a mulher através do matrimônio, direcionando-a a salvação através dos rígidos códigos de conduta impostos pela Igreja Católica. 
Com efeito, as construções da mulher imaculada, perversa e submissa ao homem são reverberadas ao longo dos séculos. A literatura, de acordo com Mignolo (2001), em Lógica das Diferenças e Políticas das semelhanças da Literatura que parece História ou Antropologia, e vice-versa, como expressão que testemunha as práticas sociais e políticas de uma determinada época oferece ao leitor subsídios para compreender o presente através do passado, isto é, compreender o machismo/patriarcado a partir do "Tratado do Amor Cortês".

Em “O que é a que é?", o eu lírico lança mão de versos que apresentam um ideal de mulher estereotipada, em que lhe denominaram de imaculada (Domingo. dia do Senhor. não descansa), de mãe (Produz pouco porque já reproduz e isso lhe basta), de coadjuvante (Se for grande é porque está por detrás de um grande homem) e de invejosa (Suas tentativas de participação recebem como intromissão). Estas concepções, além de resíduos de uma perspectiva medieval, constroem um contexto social brasileiro dos anos de 1980, ano do lançamento da obra Navalhanaliga, dentro do qual foi projetada no poema uma sociedade opressora e patriarcal.

A música "Ladainha”, de Alice Ruiz, foi gravada pela intérprete Alzira Espíndola e lançada no álbum Paralelas (2006). A canção expressa um perfil de mulher que reflete sobre a sua própria autonomia na conduta amorosa: 
Era uma vez uma mulher

Que via um futuro grandioso

Para cada homem que a tocava

Um dia

Ela se tocou...

Eu pensava que o amor

Me faria uma rainha

E quando você chegasse

Não seria mais sozinha

Você chega da gandaia

Só pensando numazinha

Seu amor é pouca palha

Para minha fogueirinha

O que você jogou fora

É para poucos

O meu mal foi jogar

Pérolas aos porcos

Eu não sou da sua laia

Não quero sua ladainha

Pra ser mal acompanhada

Prefiro ficar na minha

A primeira estrofe da canção sugere uma atmosfera fantasiosa, próxima ao contexto dos contos de fadas (era uma vez), em que havia uma mulher que criava uma expectativa para cada homem com que ela se relacionava, o que a deixava como personagem secundária em uma conduta amorosa. Dessa maneira, a fruição e o ideal de amor (um futuro grandioso) era motivado pelo homem; no entanto, a epifania (Um dia/ ela se tocou) expressa uma ambiguidade, já que pode refletir a descoberta das suas próprias esco- 
lhas no jogo amoroso, como também a revelação de uma autossatisfação, ou seja, a não-dependência do companheiro para sentir prazer. Esta canção aborda o amor cortês na contemporaneidade a partir do protagonismo da mulher.

A canção de Alice Ruiz expressa uma perspectiva discursiva muito próxima do quadrinho "Ele precisa de mim até quando?" e do poema visual “O que é a que é?": mulheres inseridas/estereotipadas em uma sociedade machista e a ruptura da conduta amorosa a partir de uma epifania.

O poema "Sou uma moça polida", publicado no livro Dois em um (2012), apresenta uma discussão significativa em torno da condição da mulher na conduta amorosa:

Sou uma moça polida

levando

uma vida lascada

cada instante

pinta um grilo

por cima

da minha sacada (RUIZ, 2012, p.150)

O eu lírico apresenta uma consciência histórica sobre a sua própria formação enquanto mulher. 0 fato de ser "uma moça polida", qualidade esta a quem foi submetida aos valores morais, às condutas e às posturas conservadores, de origem patriarcal, é uma espécie de gatilho para um cotidiano fatigante 
(levando/uma vida lascada). Esta construção de um indivíduo feminino no poema pode ser um resíduo da mulher do período medieval, em que era subordinada aos afetos dos homens que a cortejava (cada instante) pinta um grilo/por cima/da minha sacada).

Sendo assim, o HQ Afrodite: quadrinhos eróticos (1978) e Navalhanaliga (1980), Paralelas (2006) e Dois em um (2012) são obras significativas da poeta Alice Ruiz, uma vez que, a partir de um processo estético que perverte o rigor formal de composição literária, apresentam temáticas em torno da figura da mulher e do amor. Estes eixos temáticos são expressos por um lirismo questionador e crítico, o que pode projetar no leitor uma consciência política, histórica e social pertinente à corrente feminista dos anos de 1960. Dessa maneira, o estudo da literatura como expressão do testemunho de uma época, ou de período longínquo da nossa contemporaneidade, possibilita o protagonismo das mulheres que foram e ainda são apagadas da história e da literatura.

\section{A conduta amorosa e a figura da mulher na sala de aula}

Mediar a conduta amorosa e a figura da mulher em sala de aula pode propiciar a compreensão dos discursos sociais e históricos na linguagem poética de Alice Ruiz. De acordo com Klinger (2014, p. 56), a obra literária é um lugar onde as experiências de 
vida e as vivências de mundo se encontram. Com efeito, a literatura não pode ser apenas observada como um objeto estético, mas como um espaço relevante onde o leitor/aluno é afetado por um conteúdo de nível cultural e cotidiano, contribuindo, portanto, para a produção de reverberações. Sendo assim, a leitura literária da compositora curitibana potencializa as percepções do leitor, ressoando nele os bastidores sociais e políticos de uma época.

Tendo em vista os discursos acima, o questionamento que se apresenta é: como a temática da conduta amorosa e da figura da mulher no fazer poético de Alice Ruiz pode potencializar a percepção do leitor na sala de aula? E se sim, como essas temáticas são experimentadas esteticamente no cotidiano escolar por alunos do Ensino Médio?

Dessa forma, compreender a linguagem poética e o seu poder perceptivo pode favorecer ao leitor/aluno um olhar atento para os movimentos sociais e para as práticas do cotidiano. 0 feminismo, por exemplo, impactou diversas práticas, tais como: a crítica literária, a ressignificação da identidade, a história, e o direito à liberdade. No que se refere ao direito à liberdade, percebemos que, de acordo com Hall (2011, p.46), o feminismo propiciou, nos anos de 1960, discussões de temas tabus, como, por exemplo, o corpo, o afeto, a maternidade e a sexualidade, sobre as quais as mulheres foram oprimidas a partir de um sistema patriarcal. 
É por esse contexto que fomentamos um planejamento, em que consideramos três momentos específicos com a leitura literária para que os estudantes apreendam a pluralidade da linguagem poética, como também compreendam os discursos em torno da conduta amorosa e da figura da mulher. Conforme Solé (1998), em Estratégias de leitura, é sugerível que os alunos saibam antes da leitura os objetivos, a fim de que os mesmos possam acessar os seus próprios conhecimentos prévios das temáticas elencadas, as suas vivências de mundo, as suas bagagens culturais, as suas crenças, os seus modismos e as suas experiências anteriores de leitura. Dessa maneira, o discente pode selecionar uma dessas estratégias/habilidades para a recepção do texto literário.

Para a compreensão do texto antes da leitura, o estudante precisa utilizar os seus conhecimentos prévios, os quais, de acordo com Kleiman (2002), é um conjunto de informações, ou experiências, que o aluno já vivenciou ao longo da vida.

Durante essa experiência, as atividades devem consistir em observações dos textos compartilhados entre estudantes e professores, já que, segundo Solé (1998), os alunos devem compreender as estratégias para visualizar o processo de recepção do texto literário. Sendo assim, os adolescentes terão contato com os diversos problemas elencados em cada um dos textos vivenciados em sala de aula, como também 
procurarão diferentes soluções para compreender a leitura.

Desse modo, o papel do docente é mediar as ações de leitura dos estudantes durante o processo da experiência literária. Através de questionamentos e do compartilhamento de possibilidades de leitura dos alunos, o professor proporcionará ao adolescente a organização dos pensamentos, a fim de que cada um dos discentes se torne independente no processo de leitura.

Depois da leitura, as estratégias adotadas pelo docente podem propiciar a reflexão sobre a conduta amorosa, como também a figura da mulher, relacionando as observações elencadas no processo de leitura, as experiências de leitura e as vivências de mundo com os contextos sociais, históricos e ideológicos discutidas nos bastidores da linguagem poética. Desse modo, o aluno pode criticar, refletir sobre o amor e a mulher dentro do seu contexto social, elaborar opiniões a partir da comparação dos bastidores histórico, político e social da linguagem poética de Alice Ruiz com as suas próprias experiências de mundo e fazer conexões com outros textos experimentados anteriormente.

Nesse sentido, as atividades propostas correspondem à experiência de leitura com a poética de Alice Ruiz. No entanto, podemos incluir outros poetas para favorecer a compreensão das temáticas elencadas na leitura literária. 


\subsection{Primeira sugestão de atividade}

Pelo contrário, entrego-me a ela a ponto de deixar que me inscreva no rol dos seus criados. E não me tenhais por ébrio se amo a minha boa senhora, pois sem ela não posso viver, tal o domínio que sobre mim exerce a esperança do seu amor.

Que proveito tereis, graciosa dama, em que vosso amor de mim se distancie? Parece mover-vos a vontade de ser monja. E sabei que vos amo tanto, que chego a temer que a dor me fira, se não me reparardes as injustiças de que vos acuso.

(Guilherme de Poitiers)

Estratégia: Visualização

Ano da escolaridade: $3^{\circ}$ ano do Ensino Médio

Objetivo: auxiliar o estudante na percepção da conduta amorosa e da mulher a partir da leitura oral e do compartilhamento do saber prévio em sala de aula.

\section{Recursos:}

- Texto poético de Guilherme de Poitiers.

- Leitura oral e compartilhada.

- Papel A4.

- Lápis de escrever/caneta.

- Borracha.

\section{Desenvolvimento da atividade}

\section{Antes da leitura}


O docente começará a aula pedindo aos estudantes que compartilhem as primeiras impressões sobre o que é o amor, o afeto e a mulher. Em seguida, o docente irá ler a escrita de Guilherme de Poitiers apenas uma vez. Depois, ao som de uma música romântica, ou um dedilhado de violão, o professor solicitará que os alunos fechem os olhos e lerá o mesmo texto. Esta atividade possibilitará uma percepção da temática do poema, bem como propiciará, por meio do compartilhamento das primeiras impressões, a construção do imaginário trovadoresco em torno da temática do amor e da figura da mulher.

\section{Visualização das personagens}

Título da canção:

Meu nome:

A proposta dessa canção:

\begin{tabular}{|l|l|}
\hline $\begin{array}{l}\text { Desenhe, ou escreva, a ma- } \\
\text { neira como você percebe a } \\
\text { mulher e os relacionamentos } \\
\text { amorosos. }\end{array}$ & $\begin{array}{l}\text { Desenhe, ou escreva, como é } \\
\text { a personalidade das persona- } \\
\text { gens da canção de Guilherme } \\
\text { de Poitiers. }\end{array}$ \\
\hline & \\
& \\
& \\
\hline
\end{tabular}




\subsection{Segunda sugestão de atividade}

Neste segundo momento, os alunos receberão textos impressos da poesia de Alice Ruiz, os mesmos discutidos e expostos nesse artigo, para que, em um primeiro momento, leiam silenciosamente. 0 trabalho com a leitura silenciosa, de acordo com Solé (1998), se faz significativa, uma vez que o docente observará a realização do processo de leitura como também as percepções individuais dos estudantes.

\section{Recursos:}

- Textos impressos de Alice Ruiz: "Sou uma moça polida”, "Ladainha”, “0 que é a que é?”, "Ele precisa de mim até quando?" e "navalhanaliga".

- Leitura silenciosa.

As leituras dos poemas impressos possibilitam uma reflexão acerca do sexo, da conduta amorosa e da construção da figura da mulher. Em virtude disso, o professor elencará alguns questionamentos aos alunos:

- $\quad$ texto de Guilherme de Poitiers e os poemas de Alice Ruiz abordam o quê?

- A mulher do texto de Guilherme de Poitiers é a mesma em Alice Ruiz? Quais as semelhanças e diferenças?

- A conduta amorosa é a mesma? Explique? 
- Qual é o contexto histórico do texto de Guilherme de Poitiers? Como era a sociedade daquela época?

- O contexto histórico e social presente na poética de Alice Ruiz são próximos aos de Guilherme de Poitiers? Por quê?

Os questionamentos possibilitarão a construção dos bastidores sociais e históricos do período medieval, assim como dos anos de 1980, o que pode favorecer a compreensão dos poemas, das temáticas em torno do amor cortês e da figura da mulher. Posteriormente, deve-se fazer a leitura oral e a compartilhada. A leitura oral poderia “ajudar na apreensão mais ampla do poema. No entanto, cada leitor vai, com o tempo, criando seu próprio método de leitura e enriquecendo-o também com as experiências alheias" (PINHEIRO, 2007 p.36). Já a leitura compartilhada, segundo Colomer (2002), parte da ideia de trabalhar a leitura em grupo, a fim de socializar e ampliar discussões específicas do texto literário em sala de aula.

\subsection{Terceira sugestão de atividade}

No terceiro momento, o professor poderá lançar mão de uma atividade. 0 docente irá dividir a lousa em algumas colunas. Em cada seção, ele escreverá um verso de um poema, de uma canção, ou um trecho de um quadrinho, de Alice Ruiz com a temática em torno do amor e da figura da mulher. Posteriormente, o me- 
diador vai pedir para que os estudantes escrevam as suas questões, considerações e questionamentos em um post it e os colem em um dos versos transcritos no quadro.

Essa atividade possibilitará um compartilhamento das considerações dos estudantes sobre a mulher e a conduta amorosa, como também uma discussão, uma vez que os discentes verifiquem e comparem as suas impressões e dúvidas com outros colegas. Esse compartilhamento pode propiciar a percepção discursiva do poema, já que os alunos podem responder e indagar certos questionamentos a partir do discurso do poema e das expressões poéticas. Além disso, também podem de reconstruir o imaginário de uma época através da leitura da poesia ou da canção, a fim de compreender a crítica em torno da misoginia, do machismo e das relações amorosas abusivas.

Em todas as situações, lançar mão da experiência de leitura em sala de aula através das estratégias sugeridas pode contribuir não apenas para a apreciação estética e sim para a construção de um imaginário social contemporâneo à realidade do alunado, como também compreender e criticar o preconceito, a conduta tóxica do amor cortês e figura estereotipada da mulher por meio dos bastidores da história e da literatura. 


\section{Algumas considerações finais}

Tendo em vista a discussão acima, a abordagem metodológica para a investigação da conduta amorosa e da figura da mulher na obra de Alice Ruiz gira em torno da leitura bibliográfica, cujo foco está centrado na análise da linguagem poética, como também na construção dos bastidores sociais e históricos da época dos anos de 1980.

Para verificar as temáticas mencionadas no artigo, a poética de Alice Ruiz foi analisada a partir da seguinte perspectiva: 1) análise de como são apresentadas as projeções da figura da mulher no poema lírico, no poema visual e no HQ; 2) compreensão de como a linguagem poética de Alice Ruiz aborda a conduta amorosa; 3) diálogo com os estudos medievais para compreender o amor cortês e a construção da figura da mulher ao longo da história; 4) comparação da produção literária de dois momentos históricos distintos: as poesias medievais de século XII e os escritos poéticos de Alice Ruiz, a partir de meados de 1970.

A nossa abordagem da metodologia é configurada através de uma pesquisa qualitativa, cujo foco está centrado no método de procedimento pesquisa-ação. Nesses termos, podemos entender que a abordagem qualitativa parte do fundamento de uma relação dinâmica entre o sujeito e sua realidade, ou seja, é uma relação em que há um condicionamento do meio (realidade) para o indivíduo. Determinados pressupos- 
tos compartilham da ideia de Oliveira (2008), em que o procedimento da pesquisa-ação se constitui em um tipo de pesquisa social. Neste caso, o papel do pesquisador é de comprometimento com os colaboradores/ alunos, para que, de alguma forma, as situações encontradas no processo de leitura levem a uma reflexão em torno da figura da mulher e da conduta amorosa na poesia de Alice Ruiz.

\section{Referências}

AURELL, Jaume. O Novo Medievalismo e a interpretação dos textos históricos. Roda da Fortuna. Revista Eletrônica sobre Antiguidade e Medievo, v. 4, n. 2, p. 184-208, 2015.

BARROS, José D'Assunção. 0 amor cortês - suas origens e significados. Raído, Dourados, MS, v. 5, n. 9, p. 195-216, jan./jun. 2011.

COLOMER, Teresa. A formação do leitor literário: narrativa infantil e juvenil atual. São Paulo: Global, 2002. Tradução Laura Sandroni.

DOMINGUES, Ana Beatriz Ferreira Fernandes. 0 silenciamento da mulher no discurso do amor cortês. Revista Leitura, Maceió, n. 28-29, p. 139-151, 2001.

HALL, Stuart. A identidade cultural na pós-modernidade. 11. ed. Rio de Janeiro: DP\&A, 2011. Tradução de Tomaz Tadeu da Silva, Guaracira Lopes Louro.

KLINGER, Diana. Literatura e ética: da forma para a força. Rio de Janeiro: Editora Rocco, 2014.

KLEIMAN, A. Leitura: ensino e pesquisa. 4. ed. Campinas: Pontes Editores, 2011.

LEMINSKI, Paulo; RUIZ, Alice. Afrodite: quadrinhos eróticos. São Paulo: Veneta, 2015. Roteiro de Alice Ruiz e Paulo Leminski. Organização de Worney Almeida de Souza. Pre- 
fácio de Alice Ruiz. Ilustração de Flávio Colin, Júlio Shimamoto, Claudio Seto, Marília Guasque, Rodval Matias, Morzat Cout, Eros Maichrowicz e Itamar Gonçalves.

MIGNOLO, Walter D. Lógica das diferenças e política das semelhanças: da Literatura que parece História ou Antropologia e vice-versa. In: CHIAPPINI, Lígia \& AGUIAR, Flávio Wolf de (org.). Literatura e História na América Hispânica: Seminário Interncional, 9 a 13 de setembro de 1991. 2. ed. São Paulo: Editora da Universidade de São Paulo, 2001, p. 115-134. Tradução de Joyce Rodrigues Ferraz, Ivone Daré Rabello e Sandra Vasconcelos.

ORNELLAS, Sandro. Da autonomia à Pós-autonomia: poesia como crítica do presente (notas de pesquisa). Landa, $\mathrm{v}$. 1, n², p. 132-152, 2013.

PINHEIRO, Hélder. Poesia na sala de aula. 3. ed. ampliada. Campina Grande: Bagagem, 2007.

PONTES, R. Lindes disciplinares da teoria da residualidade. Decifrar, v. 14, n. 14, p. 11-20, 2019.

RIDENTI, Marcelo Siqueira. As mulheres na política brasileira: os anos de chumbo. Tempo Social. São Paulo, n. 2, v. 2, p. 113-128, 1990.

RUIZ, Alice. Dois em um. São Paulo: Iluminuras, 2008. RUIZ, Alice. Navalhanaliga. São Paulo: iluminuras, 1980. SOLÉ, Isabel. Estratégias de leitura. 6. ed. Porto Alegre: ArtMed, 1998. Tradução de Cláudia Schilling.

SPINA, S. Apresentação da lírica trovadoresca. Rio de Janeiro: Livraria Acadêmica, 1956.

ZOLIN, Lúcia Osana. Crítica feminista e Literatura de autoria feminina. In: BONNICI, Thomas; ZOLIN, Lúcia Osana. (Org.). Teoria literária: abordagens históricas e tendências contemporâneas. Maringá: Eduem, 2009. 